\title{
The long and winding career path: lessons learned
}

\author{
Susan M. Hamman ${ }^{1}$ (D) \\ Received: 10 July 2020 / Revised: 10 July 2020 / Accepted: 4 August 2020 / Published online: 21 August 2020 \\ (C) Springer-Verlag GmbH Germany, part of Springer Nature 2020
}

After a 14-year hiatus, I returned to a professional career as a pediatric radiologist. I left private-practice general and pediatric radiology while expecting my third child, unable to balance family and work demands. The days turned into years until my children were older and I considered how to meaningfully spend my time during the rest of my life. Here I review some lessons learned in my winding career path.

\section{Stay positive and persevere}

Many were skeptical about a physician's ability to regain competence after such a long work gap. It has been an unusual career path and getting my foot back in the door was not easy. The feeling was like when I was applying to medical school years ago and had no credentials. Because any journey starts with small steps, I proceeded where openings could be found. A baseball mom friend was program director for an emergency medicine residency and invited me to give five radiology presentations for their large emergency medicine conference. She mentored me, and I attended their conference over the academic year. This led to a musculoskeletal radiology observership that got me back in the reading room and cemented my decision to return. Step by step, this led to a 6-month mini pediatric radiology fellowship through two pediatric radiologists with whom I had practiced for 5 years after my first pediatric radiology fellowship, completed 20 years earlier.

Susan M. Hamman

susham@med.umich.edu

1 Section of Pediatric Radiology, C. S. Mott Children's Hospital, Department of Radiology, Michigan Medicine,

1540 E. Hospital Drive, Room 3-233,

Ann Arbor, MI 48109-4252, USA

\section{Reassess and do not look back}

During my time away from the hospital, my family was used to me always being there. Pushback ensued upon my return to medicine, though they were generally supportive. I had to have a mindset of not letting anything get in the way, as I did in medical school. While pursuing my path back to radiology, I also looked at other options in case radiology did not work out. I earned an emergency medical technician (EMT) degree and certification. I completed a detailed career skills assessment, which recommended a career in a creative field involving people and computers. I thought that perhaps I could work as an EMT while completing a graduate degree, in case it took years to reestablish my radiology career. The skills assessment also recommended consideration of a Master of Public Health degree. This aligned well with my interests and experience in education and medicine, and I am still working on this degree. I took a comprehensive online review course, completed continuing medical education articles with self-assessment, and read books to prepare for the second fellowship. I did not look back or give up, realizing that many parents have worked continuously, often not by choice.

\section{Take nothing personally (even if it is personal)}

My goal was to practice academic pediatric radiology; I knew this was aiming extremely high based on my position at the time. A little less than 2 years ago, I was a part-time middle school cross-country coach and substitute teacher with no teaching license, though I maintained an active medical license. As noted in the quote widely attributed to the great hockey player Wayne Gretzky, "You miss 100\% of the shots you don't take." Along the way, I heard "no" a lot and took the good advice of my running friends who said to apply for everything. No clear pathway unfolded for me, unlike the experiences of my attorney and registered nurse neighbors who completed programs to return to work. I kept investigating every opportunity and tried not to let the rejections get me 
down. It was heartening how many listened to my story and helped with the many details of credentialing.

Must I do a fellowship again? If so, make it the learning experience of a lifetime and meet amazing people. Must I take another board exam? If so, learn everything possible, prove my abilities, and teach others. Must I move for a fellowship and a job? If so, think of the exciting new places, the gift of starting over, and the chance to make these decisions. My father died of lung cancer at the same age I was when I decided to return. Given this gift of life, what could be more satisfying than making a positive difference in the lives of children while fulfilling my purpose? The experience also reminded me of the extensive process international physicians undergo to practice in this country. Radiology is a great career, and it is my privilege to participate in important patient care and research again. I am so grateful for all of it and for everyone who helped get me back on track.

\section{Prioritize physical, mental and spiritual fitness}

During the time away from full-time paid employment, in addition to being able to devote attention to my family, I ran four marathons and coached seven seasons of middle school cross-country. I also coached many adult running groups and gained certification as a running coach. The consistent workouts gave me the health and stamina to accomplish the updated fellowship with its standard night and weekend duties. The motivation, perseverance and discipline required for completing a marathon have been valuable habits for returning to work. Effective coaching strategies, such as encouraging skill development in others and enthusiastic team-building, have been useful in education, collaboration and getting families and children through sometimes tough examinations.

Other pastimes, such as reading for pleasure, playing tennis, drawing and playing the guitar, helped with the inevitable stressful times that are part of the human condition. Having an established outlet for dealing with stress has been crucial. When I was in private practice with two little children and a busy physician spouse, I was functioning at full capacity to perform competently at work and see to my family's basic needs. Exercising, keeping up with the literature, cultivating friendships and engaging in creative pursuits were low priorities at the time. The addition of one more thing, such as a sick parent, a serious car accident, a child with learning differences, or a new baby - which were all factors at the time I left - can tip the balance. During my work gap, I had the privilege of time to pursue nonprofessional interests. I have the utmost respect for anyone who juggles these competing needs and moves forward. In my case, the prolonged absence from a demanding career gave me time with my family while my children were young, chances to try new things, and the opportunity to grow as a person. I can carry this with me as a complete physician because it enables me to have closer connections, empathize more and judge less.

\section{Keep it low-drama}

There can be high drama even when activities do not have high stakes, such as being on a daytime tennis team, substitute teaching or serving as a room parent. These experiences taught me about being on a team, being a leader and facing criticism graciously. Navigating these waters honed my networking, management, leadership and advocacy skills. I have tried to focus on keeping the drama low and letting go of things beyond my control.

\section{Conclusion}

My life experiences gave me insight on ways to maintain a high level of satisfaction upon returning to full-time work. I realized that creative and athletic pursuits are important to me and need to remain a priority along with my family. Building confidence through small successes and overcoming obstacles in other areas gave me the courage to reach for a seemingly insurmountable goal. The dream of practicing academic pediatric radiology, first formulated as a senior medical student, became a reality through relentless positivity, diligence and encouragement from others.

\section{Compliance with ethical standards}

Conflicts of interest None

Publisher's note Springer Nature remains neutral with regard to jurisdictional claims in published maps and institutional affiliations. 